Biochem. Lett, Vol. 6, PP. $69-79$ (2010)

\title{
EVALUATION OF MAGE-3 GENE m- RNA IN BLOOD AS POTENTIAL BIOCHEMICAL MARKER FOR HCC PATIENTS
}

\author{
Yousri M. Hussien ${ }^{1}$, Faten Z. Mohammed ${ }^{2}$, Wael \\ H. E ${ }^{3}$, Amal F. Ghareeb ${ }^{1}$ and Al-shimaa M. Abas \\ 2 \\ Medical Biochemistry, Faculty of Medicine ${ }^{1}$, Biochemistry \\ Department, Faculty of Science ${ }^{2}$, Oncology Department, \\ Faculty of Medicine ${ }^{3}$, Zagazig University, Zagazig, Egypt.
}

\begin{abstract}
ABSRACT
Hepatocellular carcinoma (HCC) is the fifth most common neoplasm in the world, and the third most common cause of cancerrelated death. Early diagnosis remains the key to effective therapy of HCC. Materials \& Methods: In the present study Alpha-fetoprotien (AFP) by ELISA technique and MAGE-3 m-RNA in blood by RTPCR were assayed in 140 individuals classified into 4 groups: control group (I) which comprised of 20 healthy individuals, group II which comprised of 20 hepatic patients without any complications; group III that comprised of 25 cirrhotic patients and group IV that comprised of 75 HCC patients. Results: The results revealed that the positive rate of $M A G E-3$ transcripts among $H C C$ patients was 36\% (27 out of 75). The results of AFP showed a significant positive increase of serum $A F P$ in group IV when compared with group I, II and III, also significant positive increase in group III when compared with group I and II.

Conclusions: MAGE-3 transcript in the blood can be used in diagnosis of HCC, to predict prognosis and monitoring of the response to the therapy, and AFP level directly correlated with progression of $\mathrm{HCC}$.
\end{abstract}




\section{INTRODUCTION}

Hepatocellular carcinoma (HCC) is the fifth most common neoplasm in the world, and the third most common cause of cancerrelated death ${ }^{[1]}$. Most cases of HCC are secondary to either a viral hepatitis infection (hepatitis B or C) or cirrhosis (2). HCC is the main cause of mortality in patients with chronic liver diseases. Therefore, cirrhotic patients are usually screened for HCC during their follow-up procedure ${ }^{(3)}$. Metastasis and recurrence after surgical resection may develop which is caused either by intrahepatic metastasis (IM) or by metachronously multicentric carcinogenesis ${ }^{(4)}$.

The reverse transcription-polymerase chain reaction (RT-PCR) has made it possible to detect molecular markers present at low copy numbers for the evaluation of micro-metastasis. MAGE gene transcripts could be used as tumor marker to specifically detect metastasis of HCC cells in peripheral blood ${ }^{(5)}$. In 1991, researchers first isolated a melanoma-associated antigen (MAGE) gene, MAGEA1. This antigen, isolated from an MZ- 2 human melanoma cell line, could be recognized by cytotoxic $\mathrm{T}$ lymphocytes (CTLs). In the following years, dozens of new MAGE gene were identified ${ }^{(6)}$. The MAGEs were further classified as belonging to either subgroup I or II. Members of subgroup I, including MAGE-A, -B, and -C, are expressed in malignant tumors and testis, but not in other normal tissues. These members are also named as cancer/ testis (CT) antigen and tumor-specific antigen. In contrast, subgroup II MAGEs are expressed in various normal adult human tissues ${ }^{(7)}$.

So this study was designed to evaluate MAGE-3 transcript and AFP levels in blood as tumor- specific biomarker for HCC patients. 


\section{*Collection of samples: \\ MATERIALS \& METHODS}

Six $\mathrm{ml}$ of venous blood was withdrawn from each individual; three $\mathrm{ml}$ of blood was collected in heparinized tube for RNA extraction for determination of MAGE-3 m-RNA. The other three ml of blood was collected in anticoagulant -free to detect AFP. 150 individuals classified into 4 groups: control group (I) which comprised of 25 healthy individuals, group II which comprised of 25 hepatic patients without any complications; group III that comprised of 25 cirrhotic patients and group IV that comprised of $75 \mathrm{HCC}$ patients.

\section{$* R N A$ extraction:}

Total RNA was extracted using simply P total RNA extracted kit.

The kit is a ready to use reagent for the isolation of total RNA from various sources including whole blood, animal/plant tissue, cultured cell and bacteria.

\section{*RT-PCR:}

Reverse transcription and PCR amplification were performed using BioRT Two Step RT-PCR Kit (No: BSB05M1). Patient,s RNA is reverse transcribed with reverse transcriptase to synthesize the cDNA using a random primer. Then the reaction is incubated at $95^{\circ} \mathrm{C}$ to inactivate the reverse transcriptase and denature the template.

The PCR technique was carried out using thermal cycler PTC100 machine (MJ Research, Inc., Watertown, Mass. USA), cycling conditions for each gene according to ${ }^{(5)}$. Each PCR reaction contains: $10 \times$ PCR buffer ( include $15 \mathrm{mM} \mathrm{Mg} 2+$ ) $(2.5 \mu \mathrm{l})$, dNTP Mixture ( $10 \mathrm{mM})(0.5 \mu \mathrm{l})$, Upstream primer $(5 \mu \mathrm{M})(0.5 \mu \mathrm{l})$, Downstream primer $(5 \mu \mathrm{M})(0.5 \mu \mathrm{l})$, Taq mix DNA polymerase $(5 \mathrm{U} / \mu \mathrm{l})(0.5 \mu \mathrm{l})$, cDNA $(2.5 \mu \mathrm{l})$ and ddH2O $(18 \mu \mathrm{l})$. Gene specific primers (PCR primers) which are not supplied by the kit were used according to ${ }^{(5)}$, supplied by (Biosynthesis, Lewisville, Texas, USA).

MAGE-3: The sequence of MAGE-3 primers and length of PCR products were as follows: MAGE-3: forward-5'-TGG AGG ACC AGA GGC CCC C-3' and reverse-5'-GGA CGA TTA TCA GGA GGC CTG C-3', size, 725 bp. 
B-actin: beta-actin gene was determined to assess the integrity of the RNA. The sequence of beta-actin primers and length of PCR products were as follows: forward-5'-GGC ATC GTG ATG GAC TCC G-3' and reverse-5'-GCT GGA AGG TGG ACA GCG A-3', size, $613 \mathrm{bp}$ ). PCR condition as the following: After initial heating at $94^{\circ} \mathrm{C}$ for $2 \mathrm{~min}, 35$ cycles of PCR were then carried out for the amplification of MAGE-3 $\left(94^{\circ} \mathrm{C}\right.$ for $45 \mathrm{~s}, 69^{\circ} \mathrm{C}$ for $45 \mathrm{~s}$, and $72^{\circ} \mathrm{C}$ for $45 \mathrm{~s}$ ). To assess the integrity of the cDNA, beta-actin was amplified for 28 cycles $\left(94^{\circ} \mathrm{C}\right.$ for $45 \mathrm{~s}, 55^{\circ} \mathrm{C}$ for $45 \mathrm{~s}$, and $72^{\circ} \mathrm{C}$ for $45 \mathrm{~s}$ ).

The amplified products were run in $2 \%$ agarose gel using the EC 360 Submarine Gel electrophoresis system (Maxicell, EC 360 ME-C apparatus Cooperation St. Petersurg. Florida USA). The results were visualized by ethidium brimide staining under ultraviolet transillumination.

The sample was considerd positive when a band was observed at $725 \mathrm{bp}$ for MAGE-3 and also B-actin was determined to assess the intergrity of the RNA where it gave a band at $613 \mathrm{bp}$, using a DNA marker (100 bp + $1.5 \mathrm{~kb}$ DNA).

\section{*Determination of serum AFP:}

The quantitative determination of the cancer antigen AFP concentration in the human serum was determined using AFP immunoassay test kit (No: 4S00068), suplied by Medical Technology Promedt Consulting GmbH, D-66386 St. Ingbert, Germany.

\section{MAGE-3 m-RNA:}

\section{RESULTS}

In group I (healthy control), MAGE-3 m-RNA could not be detected in twenty-five healthy donors. Also, similar results were obtained in group II (hepatic patients without complications) and group III (cirrhotic patients). In group IV (HCC patients), the positive rate of MAGE-3 transcript was $36 \%$ (27 out of 75$)$ and negative rate was $64 \%$ (48 out of 75) (table 1) (Fig. 1 and 2).

The distribution of MAGE-3 m-RNA expression among studied groups indicates that MAGE-3 m-RNA is tumor-specific marker, and could be detected in samples from patients with HCC (table 1). 
By using Fisher exact test, the frequency of the MAGE-3 transcript was significantly higher in group IV (HCC group) than group I, II and III $(\mathrm{P}<0.001)$.

\section{Serum AFP:}

In this study, AFP values were classified into different ranges; $0-20$; the normal range, $20-100$ and $100-1000 \mathrm{ng} / \mathrm{ml}$. In healthy control and Hepatic patients without complications group AFP level within the normal range $(0-20 \mathrm{ng} / \mathrm{ml})$. Cirrhotic patients varied in their AFP distribution, where 19 patients had AFP values between (0-20 $\mathrm{ng} / \mathrm{ml})$ and 6 patients had AFP values between $(20-100 \mathrm{ng} / \mathrm{ml})$. In HCC group, 7 patients had AFP values between $(0-20 \mathrm{ng} / \mathrm{ml})$ and 19 patients had AFP values between $(20-100 \mathrm{ng} / \mathrm{ml})$ while 49 patients had AFP values between (100-1000 ng/ml) (table 2). A significant positive increase of serum AFP was detected in HCC group compared with other groups (table 3).

Table (1): Incidence and Fisher exact test for MAGE-3 m-RNA among different groups.

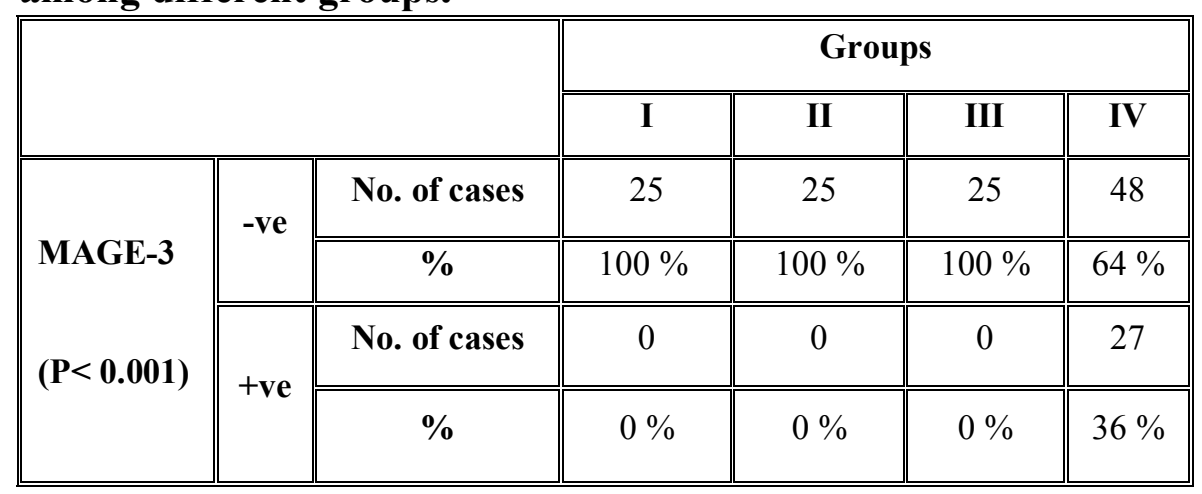




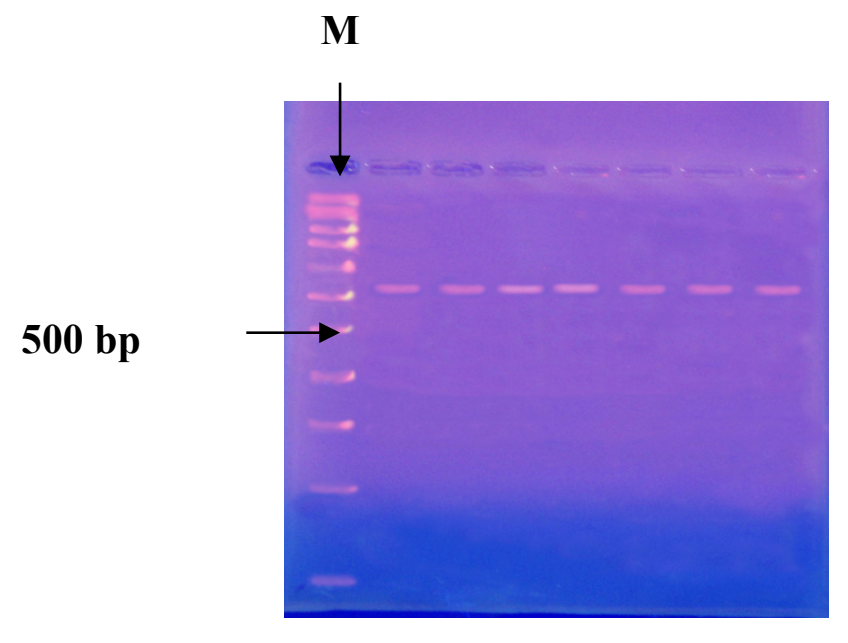

(A)

(B)

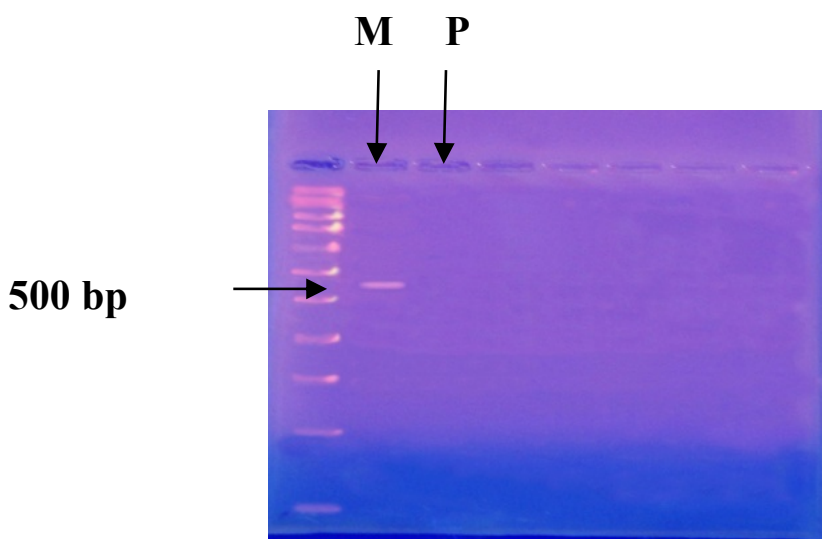

(fig 1) Electrophoresis of PCR products of MAGE-3 transcript in samples of control, hepatic patients without complications and cirrhotic patients are the same where (A) B-actin, (B) MAGE-3, M: molecular marker, $\mathrm{P}$ : positive control and all patients were MAGE-3 transcript negative. 
(A)

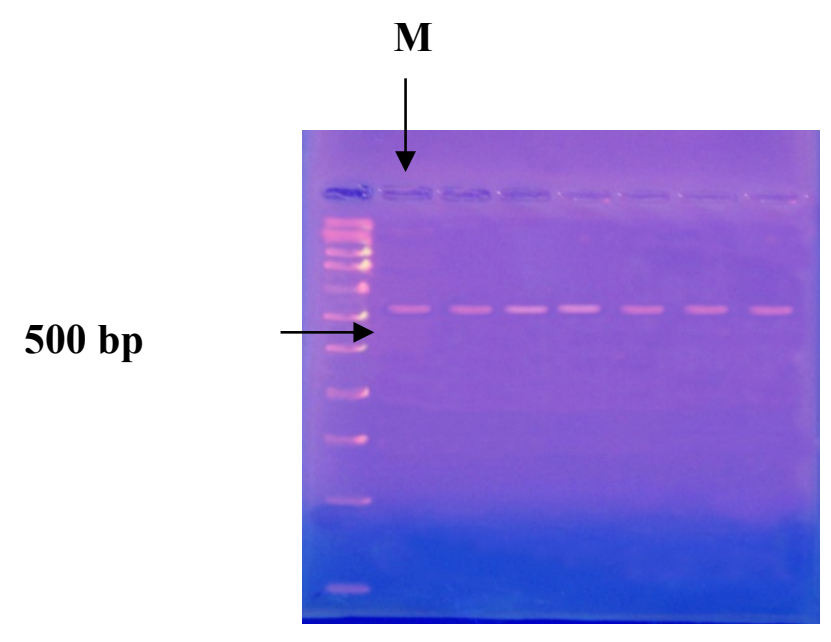

(B)

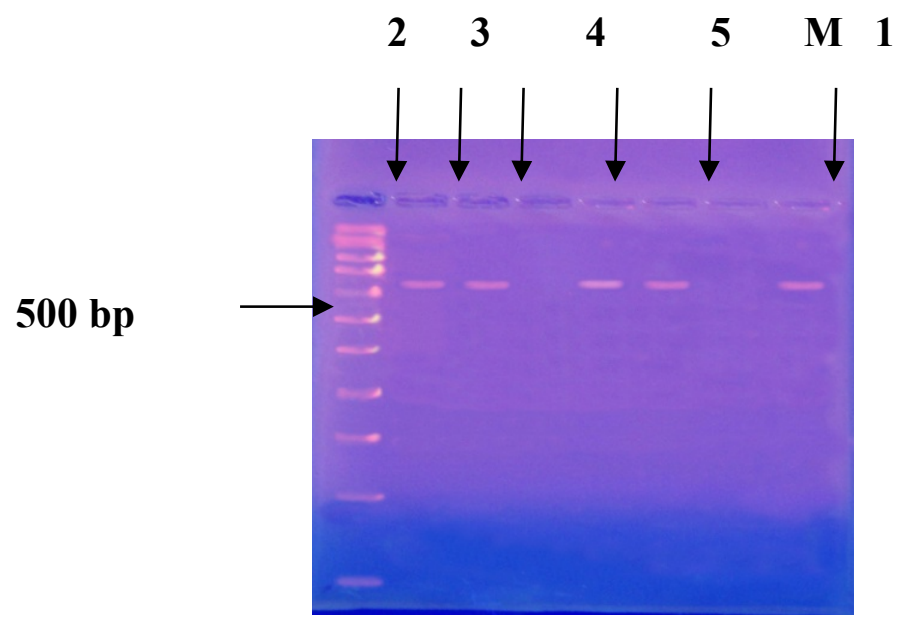

(fig 2) Electrophoresis of PCR products of MAGE-3 transcript in samples of HCC patients where (A) B-actin, (B) MAGE-3, M:

molecular marker, $\mathrm{P}$ : positive control and patient samples 1,2,3,4 and 5 showing MAGE-3 transcript positive. 
Yousri M. Hussien et al.

Table (2): Different concentration ranges of AFP in all studied groups:

\begin{tabular}{|c|c|c|c|}
\hline \multirow{2}{*}{ Patient group } & \multicolumn{3}{|c|}{ AFP concentration range (ng/ml) } \\
\cline { 2 - 4 } & $\mathbf{0 - 2 0}$ & $\mathbf{2 0 - 1 0 0}$ & $\mathbf{1 0 0 - 1 0 0 0}$ \\
\hline I & 25 & 0 & 0 \\
\hline II & 25 & 0 & 0 \\
\hline III & 19 & 6 & 0 \\
\hline IV & 7 & 19 & 49 \\
\hline
\end{tabular}

Table (3): Descriptive statistics of serum AFP (ng/ml) in all studied groups:

\begin{tabular}{|c||c||c|c|c||}
\hline $\begin{array}{c}\text { Grou } \\
\mathbf{p}\end{array}$ & $\mathbf{n}$ & Range & Mean \pm SD & P* \\
\hline \hline I & 25 & $1.99-5.30$ & $2.99 \pm 0.84$ & \\
\hline \hline II & 25 & $2.10-5.00$ & $2.89 \pm 0.81$ & \\
\hline \hline III & 25 & $2.10-52.00$ & $13.99 \pm 13.32$ & $<0.05$ \\
\hline IV & 75 & $4.06-635.00$ & $167.57 \pm 150.91$ & $<0.001$ \\
\hline
\end{tabular}

\section{Correlation coefficient:}

By using Spearman correlation between MAGE-3 m-RNA and AFP, the following results were obtained as shown in (table 4).

There is no correlation between expression of MAGE-3 m-RNA and AFP level $(\mathrm{P}>0.01)$.

Table (4): correlation between AFP and MAGE-3 transcript in HCC group.

\begin{tabular}{|l|c|c|}
\hline \multirow{2}{*}{} & \multicolumn{2}{|c|}{ MAGE-3 m-RNA } \\
\cline { 2 - 3 } & $\mathbf{r}$ & $\mathbf{P}$ \\
\hline AFP & -0.085 & 0.467 \\
\hline
\end{tabular}




\section{DISCUSSION}

This study was designed to evaluate MAGE-3 transcript and AFP level in blood as tumor- specific biomarker for HCC patients.

Determination of MAGE-3 m-RNA by RT-PCR assay revealed that MAGE-3 m-RNA could not be detected in healthy control, hepatic patients without complications and cirrhotic group while in HCC group, the positive rate of MAGE-3 transcript was $36 \%$ (27 out of 75) and negative rate was $64 \%$ (48 out of 75). It is reasonable to speculate that MAGE family proteins function during embryonic development, and then these genes are subsequently deactivated, perhaps by the epigenetic mechanisms including DNA methylation and histone deacetylation. During neoplastic transformation, these genes are re-activated, expressed, and may become antigenic targets that are recognized and attacked by the immune system ${ }^{(8)}$.

Our results are in agreement with those previously reported that in HCC patients, the positive rate of MAGE-3 mRNA expression was $33.3 \%$ in peripheral blood samples and were not detected in the adjacent non-neoplastic liver tissues or in the peripheral blood samples of cirrhotic patients without HCC and healthy subjects ${ }^{(9)}$.

As regard the obtained results of AFP showed a marked increase in HCC group compared with other groups $(\mathrm{P}<0.001)$. Also, a significant increase of serum AFP was detected in Cirrhotic group compared with Control and Hepatic patients without complications group $(\mathrm{P}<0.05)$.

Serum AFP is a widely used marker for HCC diagnosis. However, serum AFP levels are increased in patients with liver diseases other than HCC. Increases in AFP are a marker of hepatic regeneration following hepatocyte destruction in viral hepatitis ${ }^{(10)}$.

Our results are in agreement with who reported that there was a statistically highly significant elevation $(p<0.001)$ of the mean serum AFP in HCC group compared with the control, cirrhotic and HCV group ${ }^{(11)}$. 


\section{REFERENCES}

1. Parkin, D.M., Bray, F., Ferlay, J. and Pisani, P. (2001): Estimating the world cancer burden: Globocan 2000. Int. J. Cancer, 94:153-156.

2. Kumar, V., Fausto, N. and Abbas, A. (2003): Robbins \& Cotran Pathologic Basis of Disease (7th ed.). Saunders, 914-7.

3. Belghiti, J. (2005): Transplantation for liver tumors. Semin. Oncol., 32(8): 29-32.

4. Sakon, M., Nagano, H. and Nakamori, S. (2002): Intrahepatic recurrences of hepatocellular carcinoma after hepatectomy: analysis based on tumor hemodynamics. Arch. Surg., 137: 949.

5. Mou, D.C., Cai1, S.L., Peng1, J.R., Wang, Y., Chen, H.S., Pang, X.W., Leng, X.S. and Chen, W.F. (2002): Evaluation of MAGE-1 and MAGE-3 as tumour-specific markers to detect blood dissemination of hepatocellular carcinoma cells. Brit. J. Cancer. 86: $110-116$.

6. Van der Bruggen, P., Traversari, C., Chomez, P., Lurquin, C., De Plaen, E., Van den Eynde, B., Knuth, A. and Boon, T. (1991): A gene encoding an antigen recognized by cytolytic $T$ lymphocytes on a human melanoma. Science, 254: 1643-1647.

7. Chiba, T., Yokosuka, O., Kanda, T., Fukai, K., Imazeki, F., Saisho, H., Nishimura, M. and Saito, Y. (2002): Hepatic graft-versus-host disease resembling acute hepatitis: additional treatment with ursodeoxycholic acid. Liver, 22: 514-527.

8. Chomez, P., De Backer, O., Bertrand, M., De Plaen, E., Boon, T. and Lucas, S. (2001): An overview of the MAGE gene family with the identification of all human members of the family. Cancer Res., 61(14): 5544-51.

9. El Aggan, H.A., Mahmoud, S., El Delgawy, W., El Deeb, N. Shams El Din, R. (2011): MAGE-1 and MAGE-3 mRNA 
expressions as molecular biomarkers in patients with hepatitis $\mathrm{C}$ virus-related hepatocellular carcinoma. International journal of Gastroenterology and Hepatol., 60(1): A229- A230.

10. Hu, K.Q., Kyulo, N.L., Lim, N., Elhazin, B., Hillebrand, D.J. and Bock, T. (2004): Clinical significance of elevated alphafetoprotein (AFP) in patients with chronic hepatitis C, but not hepatocellular carcinoma. Am. J. Gastroenterol., 99:860-5.

11. Gameel, M., El Assaly, N., Madani, H., El-Ashry, N., Mostafa, I., Abd El Raof, E. and El-Rasky, M. (2009): Evaluation of Tumor Markers Panel in Detection of HCC in HCV Egyptian Patients and its Correlation with AFP. Research Journal of Medicine and Medical Sciences, 4(2): 402-410. 